\title{
Longitudinal ventilatory ratio monitoring for COVID-19: its potential in predicting severity and assessing treatment response
}

\author{
Natsuko Kaku ${ }^{1,4}$, Yu Nakagama', Michinori Shirano ${ }^{3}$, Sari Shinomiya ${ }^{4}, K^{1}$ Kazuhiro Shimazu ${ }^{4}$, Katsuaki Yamazaki $^{5}$, \\ Yoshito Maehata ${ }^{4}$, Ryo Morita ${ }^{3}$, Yuko Nitahara' ${ }^{1}$, Hiromasa Yamamoto ${ }^{2}$, Yasumitsu Mizobata ${ }^{2}$ and \\ Yasutoshi Kido ${ }^{1 *}$ (D)
}

\section{To the Editor:}

We read with great interest the recent research article, published in Critical Care: "Longitudinal changes in compliance, oxygenation and ventilatory ratio in COVID19 versus non-COVID-19 pulmonary acute respiratory distress syndrome", by Beloncle and collaborators [1]. We agree with their conclusion that increase in ventilatory ratio (VR) during the first week of illness is characteristic to COVID-19 ARDS and reflects its uniqueness in pathophysiology. In addition, we herein wish to propose that VR in COVID-19 ARDS may serve as a potential bedside marker reflecting clinical severity and that its longitudinal monitoring may harbor prognostic value.

In our 28-day observational study including 39 patients with critically ill COVID-19 [2], longitudinal increase in VR values were associated with failure in discontinuing respiratory support (Fig. 1). Upon predicting failure, a VR threshold of 1.56 achieved the highest predictivity with a sensitivity of 0.667 and a specificity of 0.762 on day 5 of respiratory support. Of 21 patients with a VR value lower than 1.56 on day 5,17 had successfully extubated within 28 days from respiratory support, suggesting

This comment refers to the article available online at https://doi.org/10.1186/ s13054-021-03665-8

\footnotetext{
*Correspondence: kido.yasutoshi@med.osaka-cu.ac.jp

1 Department of Parasitology, Research Center for Infectious Disease

Sciences, Graduate School of Medicine, Osaka City University, 1-4-3

Asahimachi, Abeno-ku, Osaka 545-8585, Japan

Full list of author information is available at the end of the article
}

that longitudinal VR monitoring could predict better outcome in COVID-19. Similar findings were obtained in another research applying VR changes from day 0 to 3 of respiratory support as a prognostic indicator [3]. Although statistically insignificant, Beloncle and collaborators have also shown an apparent trend towards better prognosis for a lower VR (Table S3; mortality in "VR $<2$ " versus "VR $\geq 2$ " were $15.5 \%$ versus $30 \%$ ). It would be of great interest to validate our observations in their cohort as well, by assessing longitudinally the prognostic value of VR, if sufficient data were provided. The wide variety of VR values observed along the chronological course of COVID-19 ARDS, shown in Fig. 1D, may indicate the variable responses following therapeutic interventions. The expanding but yet investigatory list of therapeutics against COVID-19 warrants a deeper description of the therapeutic interventions received within the cohort.

Elevation in VR, a surrogate marker of the increasing dead space fraction, is attributed to the progressive exudative damage affecting the alveoli, as well as the development of micro-embolism in the pulmonary circulation $[4,5]$, both known histopathological determinants of COVID-19 clinical severity. In addition to the here proposed prognostic value of VR monitoring in predicting natural history of COVID-19, future interest resides in whether longitudinal evaluation of VR may further reflect clinical response to treatment. original author(s) and the source, provide a link to the Creative Commons licence, and indicate if changes were made. The images or other third party material in this article are included in the article's Creative Commons licence, unless indicated otherwise in a credit line to the material. If material is not included in the article's Creative Commons licence and your intended use is not permitted by statutory regulation or exceeds the permitted use, you will need to obtain permission directly from the copyright holder. To view a copy of this licence, visit http://creativecommons.org/licenses/by/4.0/. The Creative Commons Public Domain Dedication waiver (http://creativeco mmons.org/publicdomain/zero/1.0/) applies to the data made available in this article, unless otherwise stated in a credit line to the data. 


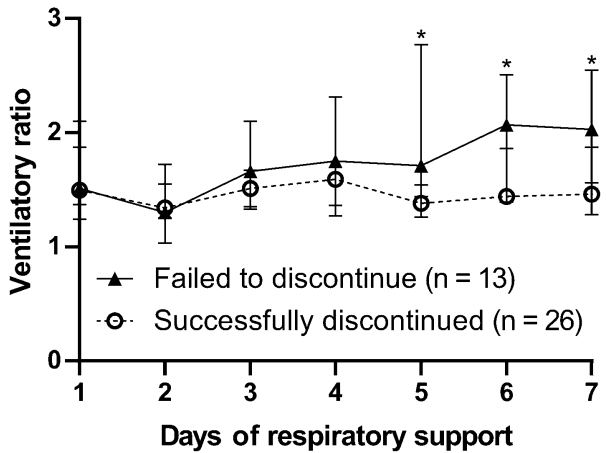

Fig. 1 Longitudinal VR values after initiation of respiratory support. Longitudinal daily values of VR during the first week after initiation of respiratory support. The failed to discontinue group presented as the solid triangles and solid lines, and the successfully discontinued group presented as the opened circles and the dashed lines. Each marker placed on the median value, and each error bar meant the $95 \%$ confidential interval. Statistical analysis determined the differences between the failed to discontinue and successfully discontinued groups on each day by Mann-Whitney test. ${ }^{*} p$-value $<0.05$

\section{Authors' response letter}

François Beloncle, Antoine Studer, Valérie Seegers, Jean-Christophe Richard, Christophe Desprez, Nicolas Fage Hamid Merdji, Bertrand Pavlovsky, Julie Helms, Sibylle Cunat, Satar Mortaza, Julien Demiselle, Laurent Brochard, Alain Alain Mercat and Ferhat Meziani

\section{Dear editor,}

We thank Drs Natsuko Kaku et al. for their interest in our study "Longitudinal changes in compliance, oxygenation and ventilatory ratio in COVID-19 versus non-COVID-19 pulmonary acute respiratory distress syndrome" that was recently published in Critical Care [1]. We also thank them for their valuable comment, in which they point out that an increase in Ventilatory Ratio (VR), a surrogate marker of an increase in dead space fraction [6], may allow to predict a poor outcome in patients with COVID-19 associated acute respiratory distress syndrome (ARDS).

We found in our cohort of 135 patients with COVID-19 associated ARDS that VR at day 1, day 3 and day 7 after intubation was higher in non-survivors than in survivors at day $28(2.1[1.7-2.4]$ vs 1.7 [1.5-2.0], $p=0.006 ; 2.4$ [2.1-2.8] vs $1.9[1.6-2.2], p=0.003$ and $3.2[2.3-3.9]$ vs 2.3 [1.8-2.7], $p=0.001$, respectively). Discrepancies between the two cohorts might be related to different time course evolutions which may be due to potential differences in non-invasive oxygenation strategies before intubation.
However, in line with the results reported by Drs. Natsuko Kaku et al., we found in patients with COVID-19 that the increase in VR from day 1 to day 7 tended to be higher in the non-survivors than in the survivors at day $28(0.8[0.3-1.8]$ vs $0.5[0.1-0.9], p=0.053)$. This tendency was not observed in the control patients with nonCOVID-19 pulmonary ARDS. High VR are known to be associated with poor outcomes in patients with nonCOVID-19 ARDS [6, 7]. Even if it has to be confirmed in larger cohorts, the potential specific prognostic value of the changes in VR over time in COVID-19 associated ARDS may be consistent with the distinct evolution of clinical features observed in this population during the first week of mechanical ventilation. As highlighted in our paper, this particular evolution may be in part due to different ventilatory strategies (in particular of positive end-expiratory pressure (PEEP) titration). We agree with Drs. Natsuko Kaku et al. that whether VR changes may help the clinicians to assess the efficacy of some therapeutics as PEEP levels or prone positioning is an interesting question which remains to be addressed.

\section{Abbreviations}

COVID-19: Coronavirus disease of 2019; ARDS: Acute respiratory distress syndrome; VR: Ventilatory ratio; ROC: Receiver operating characteristic.

\section{Acknowledgements \\ I am grateful to FORTE science communications for the manuscript revision. I would like to thank the members of Osaka City General Hospital, where the main results of this paper were obtained, especially Dr. T. Nishida and Dr. T. Shigemoto. I would also like to take this opportunity to thank Dr. T. Akamine, Dr. E. Kataoka-Nakamatsu, Dr. R. Uchida, and Dr. Y. Morimoto for their kind supports.}

\section{Authors' contributions}

NK, MS, and YK designed the concept of the study. NK, SS, KY, KS, YM, and RM conducted the study and performed the data acquisition. NK, YN, YN, and $Y K$ assessed the quality of the study and performed the analysis and interpretation. NK, YN, and YK wrote the manuscript, and the other authors made substantial revisions and edits. All authors read and approved the final manuscript.

\section{Funding}

This work was funded by Japan Agency for Medical Research and Development (AMED) under Grant number JP20wm0125003 (YK), JP20he1122001 (YK), JP20nk0101627 (YK), and JP20jk0110021 (YN). This work was also supported by JSPS KAKENHI Grans Number JP21441824 (NK). We also receive the COVID-19 Private Fund (to the Shinya Yamanaka laboratory, CiRA, Kyoto University). We received support from Osaka City University's "Special Reserves" fund for COVID-19.

\section{Availability of data and materials}

The datasets analyzed in our study are available at https://www.medrxiv.org/ content/10.1101/2021.07.20.21260754v1.supplementary-material.

\section{Declarations}

\section{Ethics approval and consent to participate}

This study was conducted under the approval of the Institutional Review Board of Osaka City University (\#2020-003) and the Clinical Research Ethics Committee of the Osaka Municipal Hospital Organization (\#2005020), Osaka, 
Japan. All necessary patient consent has been obtained and the appropriate institutional form has been archived.

\section{Consent for publication}

Not applicable.

\section{Competing interests}

Not applicable.

\section{Author details}

${ }^{1}$ Department of Parasitology, Research Center for Infectious Disease Sciences, Graduate School of Medicine, Osaka City University, 1-4-3 Asahimachi, Abeno-ku, Osaka 545-8585, Japan. ${ }^{2}$ Department of Traumatology and Critical Care Medicine, Graduate School of Medicine, Osaka City University, 1-4-3 Asahimachi, Abeno-ku, Osaka 545-8585, Japan. ${ }^{3}$ Department of Infectious Diseases, Osaka City General Hospital, Osaka City Hospital Organization, 2-13-22 Miyakojima-hondori Miyakojima-ku, Osaka 534-0021, Japan. ${ }^{4}$ Department of Anesthesia and Intensive Care Medicine, Osaka City General Hospital, Osaka City Hospital Organization, 2-13-22 Miyakojima-hondori Miyakojima-ku, Osaka 534-0021, Japan. ${ }^{5}$ Department of Anesthesiology, National Cerebral and Cardiovascular Center Hospital, 6-1 Kishibe-Shimmachi, Suita, Osaka 564-8565, Japan.

Received: 13 August 2021 Accepted: 18 August 2021

Published online: 20 October 2021

\section{References}

1. Beloncle F, Studer A, Seegers V, Richard J-C, Desprez C, Fage N, et al. Longitudinal changes in compliance, oxygenation and ventilatory ratio in COVID-19 versus non-COVID-19 pulmonary acute respiratory distress syndrome. Crit Care. 2021;25(1):248.
2. Kaku N, Nakagama Y, Shirano M, Shinomiya S, Shimazu K, Yamazaki K, et al. Increase in ventilatory ratio indicates progressive alveolar damage and suggests poor prognosis in severe COVID-19: a single-center retrospective observational study. medRxiv. 2021. https://doi.org/10.1101/ 2021.07.20.21260754.

3. the PRoVENT-COVID Study Group, Morales-Quinteros L, Neto AS, Artigas A, Blanch L, Botta $M$, et al. Dead space estimates may not be independently associated with 28-day mortality in COVID-19 ARDS. Crit Care. 2021;25(1):171.

4. Bösmüller H, Matter M, Fend F, Tzankov A. The pulmonary pathology of COVID-19. Virchows Arch. 2021:478(1):137-50.

5. Menter T, Haslbauer JD, Nienhold R, Savic S, Hopfer H, Deigendesch N, et al. Postmortem examination of COVID-19 patients reveals diffuse alveolar damage with severe capillary congestion and variegated findings in lungs and other organs suggesting vascular dysfunction. Histopathology. 2020;77(2):198-209.

6. Sinha P, Calfee CS, Beitler JR, Soni N, Ho K, Matthay MA, et al. Physiologic Analysis and Clinical Performance of the Ventilatory Ratio in Acute Respiratory Distress Syndrome. Am J Respir Crit Care Med. 2019;199:333-41.

7. Morales-Quinteros L, Schultz MJ, Bringué J, Calfee CS, Camprubí M, Cremer $\mathrm{OL}$, et al. Estimated dead space fraction and the ventilatory ratio are associated with mortality in early ARDS. Ann Intensive Care. 2019;9:128.

\section{Publisher's Note}

Springer Nature remains neutral with regard to jurisdictional claims in published maps and institutional affiliations.
Ready to submit your research? Choose BMC and benefit from:

- fast, convenient online submission

- thorough peer review by experienced researchers in your field

- rapid publication on acceptance

- support for research data, including large and complex data types

- gold Open Access which fosters wider collaboration and increased citations

- maximum visibility for your research: over $100 \mathrm{M}$ website views per year

At BMC, research is always in progress.

Learn more biomedcentral.com/submissions 